\title{
Article \\ Gender Differences in the Associations of Plasma Pyridoxal 5'-Phosphate with Plasma Polyunsaturated Fatty Acids among US Young and Middle-Aged Adults: NHANES 2003-2004
}

\author{
Hyojung Kim ${ }^{1}{ }^{\mathbb{D}}$, Evelyn B. Enrione ${ }^{1}$, Vijaya Narayanan ${ }^{1}$, Tan $\mathrm{Li}^{2}$ and Adriana Campa ${ }^{1, * \mathbb{C}}$ \\ 1 Department of Dietetics and Nutrition, Robert Stempel College of Public Health and Social Work, \\ Florida International University, Miami, FL 33199, USA; hkim030@fiu.edu (H.K.); enrionee@fiu.edu (E.B.E.); \\ vijaya.narayanan@fiu.edu (V.N.) \\ 2 Department of Biostatistics, Robert Stempel College of Public Health and Social Work, \\ Florida International University, Miami, FL 33199, USA; tanli@fiu.edu \\ * Correspondence: campaa@fiu.edu; Tel.: +1-305-348-2871
}

Citation: Kim, H.; Enrione, E.B.; Narayanan, V.; Li, T.; Campa, A. Gender Differences in the Associations of Plasma Pyridoxal 5'-Phosphate with Plasma Polyunsaturated Fatty Acids among US Young and Middle-Aged Adults: NHANES 2003-2004. Nutrients 2021, 13, 477. https://doi.org/10.3390/ nu13020477

Received: 21 December 2020

Accepted: 25 January 2021

Published: 31 January 2021

Publisher's Note: MDPI stays neutral with regard to jurisdictional claims in published maps and institutional affiliations.

Copyright: () 2021 by the authors. Licensee MDPI, Basel, Switzerland. This article is an open access article distributed under the terms and conditions of the Creative Commons Attribution (CC BY) license (https:// creativecommons.org/licenses/by/ $4.0 /)$

\begin{abstract}
Vitamin B6-restricted diets and low plasma pyridoxal 5' -phosphate (PLP) status altered plasma polyunsaturated fatty acids (PUFA) compositions. Evidence suggests the role of gender in the metabolism of vitamin B6 and PUFA. However, no epidemiologic study examined the impact of gender on the relationship between vitamin B6 and PUFA status in adults. Thus, we investigated whether there were gender differences in the association of vitamin B6 intake and plasma PLP concentration with plasma PUFA concentrations and ratios (eicosapentaenoic acid (EPA), docosahexaenoic acid (DHA), arachidonic acid (AA), EPA + DHA, EPA/AA, (EPA + DHA)/AA) in US young/middleaged adults. In total, 864 participants (20-59 years; 484 men, 380 women) from the National Health and Nutrition Examination Survey (NHANES) 2003-2004 were used for this cross-sectional study. Nutrient intakes were estimated from two $24 \mathrm{~h}$ recalls and supplement questionnaires; plasma PLP and PUFA were measured. Multivariate linear regression was utilized to obtain unstandardized (b) and standardized $(\beta)$ coefficients. Covariates included demographic, socioeconomic, dietary variables, physical activity level, cigarette smoking status, alcohol consumption, prescription medication use, and BMI. There were significant interactions between gender and PLP on EPA $\left(P_{- \text {interaction }}=\right.$ $0.004)$, DHA $(P$-interaction $=0.020), \mathrm{EPA}+\mathrm{DHA}\left(P_{\text {-interaction }}=0.010\right), \mathrm{EPA} / \mathrm{AA}\left(P_{\text {-interaction }}=0.002\right)$, $(\mathrm{EPA}+\mathrm{DHA}) / \mathrm{AA}(P$-interaction $=0.004)$, whereas no interaction between gender and B6 intake existed. In gender-stratified analyses, in men, PLP was positively associated with EPA $(\beta=0.138, \mathrm{~b}=0.104$, $p=0.0004)$, DHA $(\beta=0.101, \mathrm{~b}=0.058, p=0.036), \mathrm{EPA}+\mathrm{DHA}(\beta=0.125, \mathrm{~b}=0.073, p=0.005), \mathrm{EPA} / \mathrm{AA}$ $(\beta=0.144, \mathrm{~b}=0.099, p=0.0002),(\mathrm{EPA}+\mathrm{DHA}) / \mathrm{AA}(\beta=0.123, \mathrm{~b}=0.068, p=0.005)$. However, no associations between PLP and PUFA existed in women. In conclusion, gender differences were found in the relationships between plasma PLP and plasma EPA, DHA, EPA + DHA, EPA/AA, and (EPA + DHA)/AA, with significant direct associations in men only among US young/middle-aged adults.
\end{abstract}

Keywords: gender; vitamin B6; pyridoxal 5'-phosphate; polyunsaturated fatty acid; NHANES

\section{Introduction}

The interrelationship between vitamin B6 (B6) and unsaturated fatty acid metabolism was recognized in the 1930s [1-3]. Since then, animal studies have demonstrated that vitamin B6 deficiency alters plasma and tissue n- 3 and n-6 polyunsaturated fatty acids (PUFA) profiles, suggesting the potential metabolic link between vitamin B6 and PUFA [4-8]. In male rats fed B6-restricted diets, linoleic acid (LA; 18:2n-6) increased, but arachidonic acid (AA; 20:4n-6) decreased in plasma and liver phospholipids compared to controls [4]. Similarly, another study reported an increase in LA and a decrease in AA in liver microsomal and plasma total lipids in B6-deficient male rats [7]. Tsuge et al. [8] further showed the lower contents of eicosapentaenoic acid (EPA; 20:5n-3), docosahexaenoic acid (DHA; 
22:6n-3), and AA in plasma total lipids in B6-deficient male rats compared to pair-fed controls. Moreover, epidemiologic studies have indicated that low levels of circulating pyridoxal 5'-phosphate (PLP) change the compositions of PUFA in serum or plasma [9-12]. A clinical study with 23 healthy men and women combined (20-40 years) found that marginal vitamin B6 deficiency (plasma PLP concentration between 20 and $30 \mathrm{nmol} / \mathrm{L}$ ), which was induced by a 28 day B6-restricted diet, reduced plasma concentrations of EPA, DHA, and AA and increased slightly plasma n-6/n-3 PUFA ratio [10]. Thus, the data from animal and human studies thus far suggest that vitamin B6 deficiency may adversely affect PUFA compositions [4-12].

PUFA, such as EPA, DHA, and AA, provide beneficial functions as important constituents of cell membrane for human development and optimal health [13-16] and play a critical role in immunomodulatory function in humans [13,15-17]. Gender may influence the endogenous synthesis of n-3 and n-6 PUFA [18-23], and women may have a higher metabolic capacity to convert $\alpha$-linolenic acid (ALA; 18:3n-3) into longer chain n-3 PUFA in blood lipids than men [13,22-24]. Two stable isotope studies [22,23] on fatty acid metabolism with six young women ( $28 \pm 4$ years) [22] and with six young men (27-40 years) [23] reported that, in women, the estimated net fractional interconversion of the tracer [U-13 C]ALA to EPA was $21 \%$, and to DHA was 9\% [22]. In contrast, in men, the estimated values were $8 \%$ for EPA and non-detectable for DHA, implying the inhibition or the restriction of DHA synthesis for men [23]. Similarly, a cross-sectional study of the 1997 National Nutrition Survey with 2793 New Zealanders ( $\geq 15$ years) showed a higher proportion of DHA but a lower EPA in serum phospholipids in women than in men [18]. Further, a recent meta-analysis found higher contributions of DHA and AA to plasma total lipids and plasma phospholipids in women than in men [14].

Based on the described evidence regarding the interaction between vitamin B6 and PUFA metabolism and the differential PUFA compositions by gender, it may be plausible that gender may contribute to the relationship between PUFA levels, vitamin B6 intake, and B6 status, measured by PLP. Both vitamin B6 status $[25,26]$ and PUFA levels such as EPA and DHA [15,27] have been shown to be inversely associated with inflammation; it has been suggested that gender differences exist in inflammatory diseases such as cardiovascular diseases [28-30]. Thus, understanding the relationship between gender, vitamin B6, and PUFA has important public health implications. However, data indicating the interconnection between gender, vitamin B6, and PUFA are sparse. Therefore, we aimed to investigate whether the association of vitamin B6 intake and plasma PLP level, respectively, with plasma PUFA levels differed by gender in a large representative sample of adults aged 20-59 years from the National Health and Nutrition Examination Survey (NHANES) 2003-2004.

\section{Materials and Methods}

\subsection{Data Source and Study Population}

This study is a cross-sectional study utilizing the NHANES data, which follow a stratified, multistage, clustered probability sampling design. The 2003-2004 cycle was utilized since all the main independent and dependent variables of interest were available only in this dataset (especially plasma PLP and plasma PUFA). The NHANES, conducted by the National Center for Health Statistics (NCHS), is designed to obtain nationally representative information on the health and nutritional status of the civilian non-institutionalized US population [31].

Written informed consent was obtained from all participants [32], and the survey protocol was approved by the Research Ethics Review Board of the NCHS [33]. Participants were interviewed by trained staff for collecting household interview data, including demographic, socioeconomic, dietary supplements, and prescription drug data, via a computer-assisted personal interview (CAPI) system [32]. The participants were invited to the mobile examination center (MEC), where anthropometric, reproductive history, and 
other health-related data were collected [32]. In the MEC laboratory, blood specimens were processed and shipped to corresponding laboratories for analysis [34].

From the total 10,122 participants in the NHANES 2003-2004, participants aged $\geq 20$ years with fasting $(\geq 8 \mathrm{~h}$ ) blood samples were used in this study $(n=4034)$. Of these, 1829 participants had measurements of plasma concentrations of ALA, LA, EPA, DHA, or AA. Of these, participants aged 20-59 years numbered 1141. The data from adults aged 20-59 years were used since the aging process may alter lipid metabolism by reducing fat oxidation and free fatty acid mobilization $[35,36]$ and changing blood PUFA levels [37-39].

We excluded participants with dietary recalls which were unreliable or not met the minimum criteria $(n=3)$. Plasma PLP level may be influenced by diabetes [40], liver diseases [40], the current uses of oral contraceptives (OC) [40,41], and hormone replacement therapy (HRT) [41]; plasma PUFA levels may also be altered by the uses of oral [21] or injectable [42] (e.g., Depo-Provera) contraceptives and HRT [43]. For this reason, participants with physician-diagnosed diabetes or hemoglobin A1C (A1C) $\geq 6.5 \%$ or fasting plasma glucose $\geq 126 \mathrm{mg} / \mathrm{dL}$ ( $n=76$ ) or current liver diseases $(n=20)$, current use of HRT $(n=39)$, or oral/injectable contraceptives $(n=52)$ were excluded. Pregnant $(n=87)$ or lactating $(n=15)$ women were also excluded since hormonal changes may lower plasma PLP levels during pregnancy and lactation [40] and may alter plasma PUFA levels during pregnancy $[44,45]$.

Consequently, the final resulting analytic sample size was 864 participants (484 men, 380 women). Depending on nonpositive weights, missing data (the responses of "refused" or "don't know" were treated as missing), and/or model covariates, the samples for descriptive and regression analyses were available from 674 to 864 participants. Of the final analytic sample, the proportion of men was higher than women $(55.4 \%$ for men vs. $44.6 \%$ for women), which came from excluding women with the current use of HRT, oral/injectable contraceptives, or with pregnancy or lactation. A flow chart describing the sample selection is presented in Figure 1.

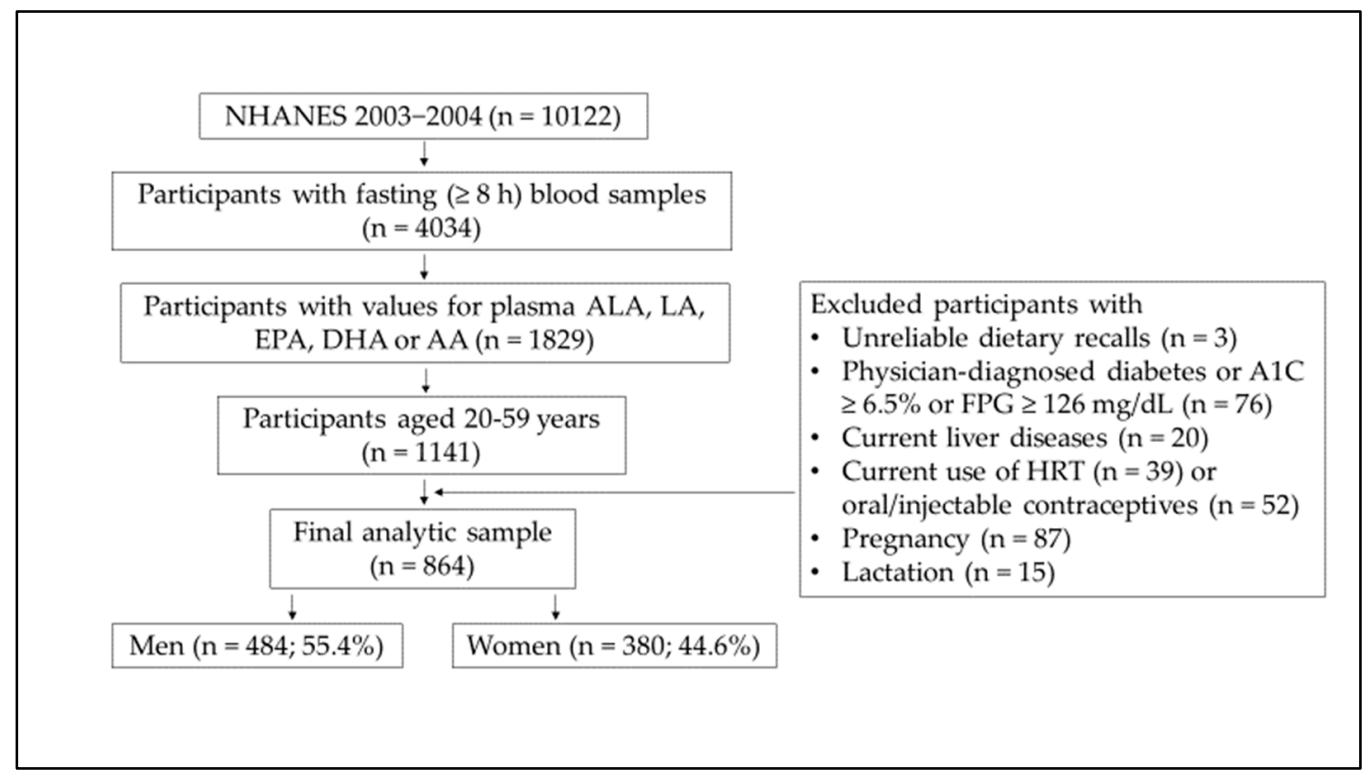

Figure 1. Flow chart of National Health and Nutrition Examination Survey (NHANES) 2003-2004 analytic sample. A1C, hemoglobin A1C; FPG, fasting plasma glucose; HRT, hormone replacement therapy; \%, sample-weighted percentage; sample sizes $(n)$ were presented as unweighted.

\subsection{Assessment of Vitamin B6 and PUFA Intakes from Food and Supplements}

According to the NHANES documentation [46], collection of two days of dietary intake data was performed by trained staff; a first $24 \mathrm{~h}$ recall interview at MEC was used for the first day's data and a second $24 \mathrm{~h}$ recall interview by telephone $3-10 \mathrm{~d}$ after the MEC 
examination for the second day's data. Participants completed both dietary interviews using the US Department of Agriculture's Automated Multiple-Pass Method (AMPM) [46].

Personal interview data on the use of vitamins, minerals, and other dietary supplements (supplement name, ingredients, amounts, and serving size) were recorded by the interviewer [47]. Participants were asked duration, frequency, and daily amount in the past 30 days of dietary supplement use [48]. NCHS obtained product label information for dietary supplements from the manufacturer/retailer, the Internet, company catalogs, and the Dietary Supplement Label Database (DSLD) containing the full label contents from supplement products in the US [48]. The ingredient amounts in supplement products were determined by matching the name and the manufacturer of the product to those in a database developed by NCHS and the National Institutes of Health (NIH)'s Office of Dietary Supplements [48]. Using various dietary supplement files, we identified participants who reported the use of any dietary supplements containing the ingredients of vitamin B6, EPA, DHA, and ALA. The average daily intake of these nutrients from dietary supplements was estimated for participants, using the number of days that the use of supplements was reported, the amount taken per day, and the serving size unit from the supplement product label.

The mean dietary daily intakes of vitamin B6, ALA, LA, EPA, DHA, AA, total fat, and total energy were calculated from the averages of both the first and the second day dietary recall interviews. Octadecatrienoic acid (linolenic acid; 18:3), which includes mainly $\alpha$-linolenic acid and lesser quantities of $\gamma$-linolenic acid (18:3n-6) [49], was examined. Octadecadienoic acid (LA), eicosatetraenoic acid (AA), EPA, and DHA were also assessed. Total daily intakes of vitamin B6, EPA, DHA, and ALA from food and dietary supplements were estimated by combining the mean dietary daily intake from dietary recall data and the average daily intake from dietary supplement data.

\subsection{Definition of Gender}

The terms of gender and sex are often used interchangeably in the scientific literature $[50,51]$. Sex is related to the biological distinctions that differ between men and women based on reproductive functions. In contrast, gender refers to socially and culturally constructed differences between men and women on the basis of the sex of the individual or the personal identification of an individual's own gender [50,51]. Based on the usage of gender in the codebook of NHNAES [52], the term of gender was used in this study, although this study's possible suggested mechanisms relevant to the function of vitamin B6 and PUFA are inherent to the biological differences between men and women.

\subsection{Laboratory Measurements of Plasma PLP and PUFA}

\subsubsection{Pyridoxal 5'-Phosphate (PLP)}

Homogeneous, nonradioactive, enzymatic assay (A/C Diagnostics, San Diego, CA, USA) was used for measuring plasma PLP concentration (nmol/L) [53]. The mean intraassay coefficient of variation (CV) from $7.8 \%$ to $8.3 \%$ and the mean inter-assay CV from $12.0 \%$ to $13.1 \%$ were reported [53]. Assay values below the lower limit of detection were replaced with $7.1 \mathrm{nmol} / \mathrm{L}$ (the detection limit of $10.09 \mathrm{nmol} / \mathrm{L}$ divided by the square root of 2) $[53,54]$. Plasma PLP was dichotomized by $20 \mathrm{nmol} / \mathrm{L}$ as a categorical variable because plasma PLP $\geq 20 \mathrm{nmol} / \mathrm{L}$ is the definition of vitamin B6 adequacy used to set the current estimated average requirements (EAR) and recommended dietary allowances (RDA) of vitamin B6 [55].

\subsubsection{Plasma Polyunsaturated Fatty Acids (PUFA)}

Blood samples for fatty acid concentration measurements $(\mu \mathrm{mol} / \mathrm{L})$ were collected from participants $\geq 20$ years after fasting for $\geq 8 \mathrm{~h}$. Gas chromatography-mass spectrometry was used to measure plasma fatty acids. Modified Lagerstedt et al. method was performed to measure plasma total fatty acid concentrations [56]. The mean intra-assay CV (standard deviation (SD)) for analytes was reported as $9 \%(10 \%)$ and the mean inter-assay CV (SD) 
for analytes as $8 \%(10 \%)$ [56]. In this study, we excluded subjects missing data on any individual fatty acids since this would influence the calculation of the sum of EPA and DHA and the ratios of EPA/AA and (EPA + DHA)/ AA [57].

\subsection{Study Covariates}

Since plasma PUFA levels may be influenced by the following demographic, socioeconomic variables, physical activity level, cigarette smoking status, alcohol consumption, prescription medication use, BMI [58-60], and menopausal status [61], they were selected as covariates in this study. In addition, since the consumption of fatty acids and total fat can influence PUFA profiles $[57,62,63]$, dietary factors including total fat intake and PUFA intake were included as model covariates.

\subsubsection{Demographic Factors}

Age was categorized as 20-29, 30-39, 40-49, and 50-59 years. Race/ethnicity was categorized into non-Hispanic White, non-Hispanic Black, Hispanic (Mexican American, Other Hispanic), and Others.

\subsubsection{Socioeconomic Factors}

Family poverty income ratio (PIR), an index for the ratio of annual family income to the poverty threshold, was dichotomized by 1.3. Participants with PIR below 1.3 are eligible for the Supplemental Nutrition Assistance Program [64]. Educational attainment was categorized into high school graduation or less and some college or higher.

\subsubsection{Dietary Factors}

Dietary variables, such as total intakes of vitamin B6, EPA, DHA, ALA from food and supplements, dietary intakes of LA and AA from food, and total fat intake from food, were used as covariates.

\subsubsection{Other Factors}

Cigarette smoking status was categorized as a never smoker who smoked $<100$ cigarettes in life; a former smoker who did not smoke at the time of interview among those who had smoked $\geq 100$ cigarettes in life; and a current smoker who reported ongoing smoking. Alcohol consumption was categorized as an abstainer who had $<12$ drinks of any type of alcoholic beverage in life; a former drinker who had $\geq 12$ drinks in life or any one year, but none in the past 12 months; a current drinker who had $\geq 12$ drinks in life, and drank $\geq 1$ time in the past 12 months.

Physical activity level expressed on the metabolic equivalent of task (MET) score was categorized as $<500,500-1000$, and $\geq 1000 \mathrm{MET} \mathrm{min} /$ week, which was calculated from the frequency and the duration of household/yard work, transportation, and leisure time. Prescription medication use was defined as a positive response to the question of taking any prescription medication in the past month.

Body mass index (BMI) was categorized as $<18.5,18.5-24.9,25-29.9$, and $\geq 30 \mathrm{~kg} / \mathrm{m}^{2}$. Menopause was defined to be when a woman did not have a menstrual period in the past 12 months.

\subsection{Statistical Methods}

Appropriate sample weights were applied to account for complex survey design and the unequal probability of selection, noncoverage, and nonresponse bias. Variance estimates were computed using Taylor series linearization accounting for the complex sample design. All tests were two-sided, and the significance level was set at $p<0.05$. Statistical analyses were performed with SAS 9.4 (SAS Institute Inc., Cary, NC, USA).

The dietary and the total intakes of vitamin B6, ALA, LA, EPA, DHA, and AA were energy-adjusted using the residual method to employ the regression model with total 
caloric intake as the independent variable and absolute nutrient intake as the dependent variable [65].

Plasma PLP and PUFA variables were natural log-transformed to improve normality due to skewed distributions as they were used as dependent variables. We tested the normality of the distributions of plasma PLP and PUFA (EPA, DHA, AA, EPA + DHA, $\mathrm{EPA} / \mathrm{AA},(\mathrm{EPA}+\mathrm{DHA}) / \mathrm{AA})$ variables using quantile-quantile (Q-Q) plots and skewness values in the univariate analysis. Those variables were highly skewed except plasma AA, which were slightly skewed. To improve normality, plasma PLP and PUFA variables were natural log-transformed. After the transformation, we tested the normality using the same method described above, and those variables improved normality, approaching near-normal. The use of log-transformed AA did not make significant differences in the findings compared with the use of the original metric AA.

For descriptive statistics of the aforementioned covariates for all study participants, men and women each, we estimated frequencies and sample-weighted percentages with standard errors (SE) for categorical variables and arithmetic means (nutrient intake variables) and geometric means (plasma variables) with SE for continuous variables. The characteristics between men and women were compared using Rao-Scott F-adjusted chisquare tests for categorical variables and $t$-tests for continuous variables.

Plasma PLP status is determined by vitamin B6 intake [12,40,41]; there was a positive correlation between total vitamin B6 intake and plasma PLP in all participants (correlation coefficient $(\rho)=0.26)$, men $(\rho=0.24)$ and women $(\rho=0.30)$, respectively, in this study (Table S1).

If vitamin B6 intake and plasma PLP are included together as independent variables in the model, this may lead to the unreliable estimation of regression coefficients in the fitted model due to possible multicollinearity [66]. In addition, the inclusion of B6 intake and PLP together as independent variables did not make material differences in the findings. Therefore, reported findings were from regressions using two separate models for vitamin B6 intake and plasma PLP, respectively.

To test whether gender modifies the relationship between vitamin B6 intake and plasma PLP, respectively, and plasma PUFA, we added the interaction terms of gender*B6 intake and gender*PLP each in the fully adjusted model before performing the genderstratified analysis. While the gender*B6 intake interaction was not significant, the gender*PLP interaction was significant. Thus, we evaluated the relationship between PLP and plasma PUFA using gender-stratified analysis.

Gender-stratified bivariate and multivariate linear regression analyses were performed to examine whether the association of plasma PLP concentration with plasma PUFA concentrations (EPA, DHA, AA, EPA + DHA) and ratios (EPA/AA, (EPA + DHA)/AA) differed by gender. Natural log-transformed plasma PLP and PUFA variables of interest were used in regression models after inspecting residual plots of gender-stratified models.

In the gender-specific models, the covariates were sequentially introduced in the following models. Model 0 was unadjusted. Model 1 was adjusted for demographic variables (age, race/ethnicity), BMI, dietary variables (total intakes of vitamin B6, EPA, DHA, ALA from food and supplements, dietary intake of LA and AA from food, total fat intake from food), and menopausal status (only for women). Model 2 was adjusted for all variables in model 2, plus socioeconomic variables (PIR, educational attainment), physical activity level, cigarette smoking status, alcohol consumption, and prescription medication use.

Unstandardized regression coefficients (b) with $95 \%$ confidence intervals were estimated. Standardized regression coefficient $(\beta)$ was employed to express the change in log-transformed plasma PUFA concentrations and ratios in SD for 1 SD of change in log-transformed plasma PLP concentration. For each model, the coefficient of determination, $R^{2}$, was quantified to measure the percentage of the total variability in plasma PUFA concentrations and ratios that the model explains. In the adjusted models 1 and $2, R^{2}$ was adjusted for the model's number of predictors. 
No multicollinearities were detected among independent variables in the fully adjusted gender-stratified regression models (for men: variance inflation factors (VIF) $=6.9$ for total EPA intake, VIF $=7.3$ for total DHA intake, VIF $<2.3$ for the other variables; for women: $\mathrm{VIF}=6.2$ for total EPA intake, VIF $=7.4$ for total DHA intake, VIF $<3.5$ for the other variables).

\section{Results}

\subsection{Demographic, Socioeconomic, and Other Characteristics of Participants by Gender}

Table 1 presents the participants' characteristics by gender. There were more men than women in the study population $(p=0.003)$. Over one-third of women were in the range of 40-49 years of age, with more than a quarter of men in the range of 40-49 years of age $(p=0.046)$. Gender was distributed similarly for non-Hispanic White, and there was a tendency of a higher proportion of men for Hispanic and Other groups and a lower proportion of men for non-Hispanic Black compared to women $(p=0.09)$. The prevalence of overweight was higher for men than for women, while women were more likely to be obese than men $(p=0.0004)$. Compared with men, women were more likely to have a low family income $(p=0.0496)$ and were less likely to consume alcohol $(p=0.002)$. Men tended to be more physically active than women $(p=0.06)$. More women used vitamin B6 supplements $(p=0.018)$ and prescription medications $(p=0.011)$ than men. Approximately one-fifth of the women were postmenopausal $(p<0.0001)$. On the other hand, there were no differences between men and women for educational attainment, cigarette smoking status, and n-3 PUFA supplement use.

Table 1. Demographic, socioeconomic, and other characteristics of participants by gender among US adults aged 20-59 y, NHANES 2003-2004.

\begin{tabular}{|c|c|c|c|c|c|c|c|}
\hline \multirow[b]{2}{*}{ Characteristics } & \multicolumn{2}{|c|}{ All $(n=864)$} & \multicolumn{2}{|c|}{ Men $(n=484)$} & \multicolumn{2}{|c|}{ Women $(n=380)$} & \multirow[b]{2}{*}{$p^{1}$} \\
\hline & $n$ & $\% \pm \mathrm{SE}$ & $n$ & $\% \pm \mathrm{SE}$ & $n$ & $\% \pm \mathrm{SE}$ & \\
\hline Gender & 864 & $100 \pm 0$ & 484 & $55.4 \pm 1.5$ & 380 & $44.6 \pm 1.5$ & 0.003 \\
\hline Age (years) & & & & & & & 0.046 \\
\hline $20-29$ & 227 & $21.9 \pm 1.5$ & 147 & $25.3 \pm 1.8$ & 80 & $17.7 \pm 2.1$ & \\
\hline $30-39$ & 226 & $26.6 \pm 1.6$ & 125 & $26.1 \pm 1.7$ & 101 & $27.2 \pm 3.1$ & \\
\hline $40-49$ & 253 & $31.4 \pm 1.7$ & 128 & $27.8 \pm 2.5$ & 125 & $35.9 \pm 2.4$ & \\
\hline $50-59$ & 158 & $20.1 \pm 2.1$ & 84 & $20.8 \pm 3.0$ & 74 & $19.2 \pm 2.0$ & \\
\hline Race/Ethnicity & & & & & & & 0.09 \\
\hline Non-Hispanic White & 444 & $70.9 \pm 3.7$ & 245 & $70.6 \pm 4.0$ & 199 & $71.2 \pm 3.7$ & \\
\hline Non-Hispanic Black & 180 & $10.4 \pm 1.8$ & 91 & $8.6 \pm 1.8$ & 89 & $12.6 \pm 2.2$ & \\
\hline Hispanic & 200 & $13.0 \pm 2.8$ & 123 & $14.3 \pm 3.3$ & 77 & $11.4 \pm 2.5$ & \\
\hline Others & 40 & $5.7 \pm 0.5$ & 25 & $6.4 \pm 1.0$ & 15 & $4.8 \pm 1.0$ & \\
\hline $\mathrm{BMI}\left(\mathrm{kg} / \mathrm{m}^{2}\right)$ & & & & & & & 0.0004 \\
\hline$<18.5$ & 12 & $1.6 \pm 0.4$ & 5 & $1.0 \pm 0.4$ & 7 & $2.5 \pm 0.7$ & \\
\hline $18.5-24.9$ & 264 & $31.5 \pm 1.4$ & 148 & $27.8 \pm 2.2$ & 116 & $36.2 \pm 2.5$ & \\
\hline $25-29.9$ & 294 & $34.9 \pm 2.0$ & 188 & $41.6 \pm 2.0$ & 106 & $26.5 \pm 2.8$ & \\
\hline$\geq 30$ & 283 & $32.0 \pm 1.9$ & 139 & $29.7 \pm 2.3$ & 144 & $34.9 \pm 2.9$ & \\
\hline PIR & & & & & & & 0.0496 \\
\hline$\leq 1.3$ & 216 & $19.5 \pm 1.7$ & 108 & $16.6 \pm 1.7$ & 108 & $23.1 \pm 2.8$ & \\
\hline$>1.3$ & 612 & $80.5 \pm 1.7$ & 356 & $83.4 \pm 1.7$ & 256 & $76.9 \pm 2.8$ & \\
\hline Educational attainment & & & & & & & 0.352 \\
\hline$\leq$ High school degree & 430 & $43.1 \pm 2.0$ & 252 & $45.0 \pm 2.0$ & 178 & $40.7 \pm 3.9$ & \\
\hline$>$ High school degree & 434 & $56.9 \pm 2.0$ & 232 & $55.0 \pm 2.0$ & 202 & $59.3 \pm 3.9$ & \\
\hline Physical activity (MET min/week) & & & & & & & 0.06 \\
\hline$<500$ & 343 & $35.7 \pm 2.6$ & 182 & $32.2 \pm 3.2$ & 161 & $40.0 \pm 3.4$ & \\
\hline $500-1000$ & 124 & $16.4 \pm 1.6$ & 66 & $15.3 \pm 2.4$ & 58 & $17.8 \pm 1.8$ & \\
\hline$\geq 1000$ & 397 & $47.9 \pm 2.1$ & 236 & $52.5 \pm 2.9$ & 161 & $42.3 \pm 2.6$ & \\
\hline Cigarette smoking & & & & & & & 0.16 \\
\hline Never smoker & 453 & $51.4 \pm 2.4$ & 235 & $48.0 \pm 3.1$ & 218 & $55.6 \pm 3.8$ & \\
\hline Former smoker & 150 & $18.8 \pm 2.0$ & 92 & $21.1 \pm 1.8$ & 58 & $16.0 \pm 3.3$ & \\
\hline Current smoker & 261 & $29.8 \pm 2.1$ & 157 & $30.9 \pm 2.2$ & 104 & $28.4 \pm 3.0$ & \\
\hline
\end{tabular}


Table 1. Cont.

\begin{tabular}{|c|c|c|c|c|c|c|c|}
\hline \multirow[b]{2}{*}{ Characteristics } & \multicolumn{2}{|c|}{ All $(n=864)$} & \multicolumn{2}{|c|}{ Men $(n=484)$} & \multicolumn{2}{|c|}{ Women $(n=380)$} & \multirow[b]{2}{*}{$p^{1}$} \\
\hline & $n$ & $\% \pm \mathrm{SE}$ & $n$ & $\% \pm \mathrm{SE}$ & $n$ & $\% \pm \mathrm{SE}$ & \\
\hline Alcohol consumption & & & & & & & 0.002 \\
\hline Lifetime abstainer & 89 & $9.1 \pm 1.3$ & 35 & $5.9 \pm 1.0$ & 54 & $13.2 \pm 2.0$ & \\
\hline Former drinker & 112 & $14.1 \pm 2.2$ & 54 & $12.2 \pm 2.7$ & 58 & $16.6 \pm 2.4$ & \\
\hline Current drinker & 588 & $76.8 \pm 2.9$ & 364 & $81.9 \pm 3.1$ & 224 & $70.2 \pm 3.5$ & \\
\hline Vitamin B6 supplement & & & & & & & 0.018 \\
\hline No & 619 & $66.8 \pm 1.5$ & 362 & $69.8 \pm 1.8$ & 257 & $63.1 \pm 2.1$ & \\
\hline Yes & 243 & $33.2 \pm 1.5$ & 122 & $30.2 \pm 1.8$ & 121 & $36.9 \pm 2.1$ & \\
\hline n-3 PUFA supplement & & & & & & & 0.36 \\
\hline No & 846 & $97.1 \pm 0.9$ & 477 & $97.9 \pm 1.0$ & 369 & $96.2 \pm 1.5$ & \\
\hline Yes & 16 & $2.7 \pm 0.9$ & 7 & $2.1 \pm 1.0$ & 9 & $3.8 \pm 1.5$ & \\
\hline Prescription medication & & & & & & & 0.011 \\
\hline No & 540 & $57.4 \pm 2.0$ & 332 & $62.3 \pm 2.9$ & 208 & $51.3 \pm 2.5$ & \\
\hline Yes & 322 & $42.6 \pm 2.0$ & 152 & $37.7 \pm 2.9$ & 170 & $48.7 \pm 2.5$ & \\
\hline Menopausal status ${ }^{2}$ & & & & & & & $<0.0001$ \\
\hline No & NA & NA & NA & NA & 297 & $78.1 \pm 1.5$ & \\
\hline Yes & NA & NA & NA & NA & 83 & $21.9 \pm 1.5$ & \\
\hline
\end{tabular}

BMI, body mass index; MET, metabolic equivalent of task; PIR, poverty income ratio; PUFA, polyunsaturated fatty acids; n, frequencies; \%, sample-weighted percentages, SE, standard errors; NA, not applicable. Sample sizes were presented as unweighted. Values were expressed as sample-weighted percentages $\pm \mathrm{SE} .{ }^{1}$ Rao-Scott F-adjusted chi-square tests for examining whether there are differences in proportions between men and women across categories of each characteristic. ${ }^{2}$ Rao-Scott F-adjusted chi-square tests for examining whether there are differences in proportions between premenopausal and postmenopausal status. The supplement use of vitamin B6 and n-3 PUFA, respectively, was defined as a positive response to the question of taking any dietary supplements containing vitamin B6 and n-3 PUFA (eicosapentaenoic acid (EPA), docosahexaenoic acid (DHA), $\alpha$-linolenic acid (ALA)) each in the past month.

\subsection{Distributions of the Intakes of Vitamin B6 and PUFA and the Concentrations of Plasma PUFA and PLP by Gender}

Table 2 displays distributions of the energy-adjusted dietary (from food) and total intakes (from food and supplements) of vitamin B6 and PUFA, concentrations and ratios of plasma PUFA, and concentrations of PLP by gender. Distributions of the original metric nutrient intakes were presented in Table S2. Using the residual method [65], nutrient intakes were evaluated in relation to the mean total energy intake of all study participants; the resulting measures of energy-adjusted nutrient intakes were independent of total energy intake. Due to the application of this method, overall, the energy-adjustment resulted in changes in the mean dietary intake estimates of the nutrients, with the decreased energyadjusted mean values from the original metric mean values in men and the increased energy-adjusted means from the original metric means in women. The original metric dietary vitamin B6 intake was lower in women than in men, but the energy-adjusted dietary vitamin B6 intake was similar between them, although the difference was not significant. A similar pattern was observed in the case of total vitamin B6 intake.

There was a large increase from $2 \mathrm{mg}$ of dietary vitamin B6 to $5 \mathrm{mg}$ of total vitamin B6 from food and supplements, indicating some participants were taking high dosages of vitamin B6 supplements. We observed that, among vitamin B6 supplement users ( $n=222$ without 21 nonpositive dietary sample weight), the participants greater than 95 percentiles consumed more than $58.3 \mathrm{mg} / \mathrm{d}$ of total vitamin $\mathrm{B} 6$ up to $187.0 \mathrm{mg} / \mathrm{d}$ (median: $2.5 \mathrm{mg} / \mathrm{d}$, interquartile range (IQR): $1.5-7.6 \mathrm{mg} / \mathrm{d}$; data not shown), which could affect the large increase. Meanwhile, men and women had similar total vitamin B6 intake values from food and supplements, although a higher proportion of women took vitamin B6 supplements than men. This can be explained by the greater proportion of high dosage of vitamin B6 supplement intake in men than in women. For example, among vitamin B6 supplement users, six men and two women consumed more than $100 \mathrm{mg} / \mathrm{d}$ of vitamin B6 supplements, with five extreme observations of four men and one woman (149.4, 149.5, 150.7, 152.6, $187.0 \mathrm{mg} / \mathrm{d}$; data not shown).

A mean total energy intake was lower in women than in men $(p<0.0001)$ after adjusting for demographic factors (age, race/ethnicity), socioeconomic factors (PIR, educational 
attainment), physical activity level, cigarette smoking status, alcohol consumption, prescription medication use, BMI, and menopausal status. A mean dietary ALA intake was higher in women than in men $(p=0.046)$, whereas mean dietary EPA, DHA, and AA intakes were lower in women than men ( $p=0.022, p=0.027, p=0.019$, respectively). Similarly, a mean total ALA intake from food and supplements was higher in women $(p=0.036)$, but a mean total DHA intake tended to be greater in men than in women $(p=0.06)$. Differences between men and women did not exist in dietary intakes of vitamin B6 and LA from food and total intakes of vitamin B6 and EPA from food and supplements.

Table 2. Distributions of the energy-adjusted intakes of vitamin B6 and PUFA and the plasma concentrations of PUFA and pyridoxal 5'-phosphate (PLP) by gender among US adults aged 20-59 years, NHANES 2003-2004.

\begin{tabular}{|c|c|c|c|c|c|c|c|}
\hline & \multicolumn{2}{|r|}{ All $(n=864)$} & \multicolumn{2}{|c|}{$\operatorname{Men}(n=484)$} & \multicolumn{2}{|c|}{ Women $(n=380)$} & \multirow[b]{2}{*}{$p^{1}$} \\
\hline & $n$ & Mean \pm SE & $n$ & Mean \pm SE & $n$ & Mean \pm SE & \\
\hline \multicolumn{8}{|l|}{ Nutrient intakes from food } \\
\hline Total energy $(\mathrm{kcal} / \mathrm{d})$ & 761 & $2375.2 \pm 42.0$ & 420 & $2763.2 \pm 47.4$ & 341 & $1896.1 \pm 50.0$ & $<0.0001$ \\
\hline Vitamin B6 $(\mathrm{mg} / \mathrm{d})$ & 761 & $2.05 \pm 0.04$ & 420 & $2.08 \pm 0.06$ & 341 & $2.01 \pm 0.05$ & 0.73 \\
\hline $\operatorname{ALA}(g / d)$ & 761 & $1.64 \pm 0.04$ & 420 & $1.55 \pm 0.03$ & 341 & $1.75 \pm 0.07$ & 0.046 \\
\hline $\mathrm{LA}(\mathrm{g} / \mathrm{d})$ & 761 & $16.17 \pm 0.40$ & 420 & $15.68 \pm 0.48$ & 341 & $16.78 \pm 0.40$ & 0.38 \\
\hline $\operatorname{EPA}(g / d)$ & 761 & $0.034 \pm 0.003$ & 420 & $0.039 \pm 0.005$ & 341 & $0.027 \pm 0.003$ & 0.022 \\
\hline $\operatorname{DHA}(\mathrm{g} / \mathrm{d})$ & 761 & $0.070 \pm 0.005$ & 420 & $0.078 \pm 0.008$ & 341 & $0.060 \pm 0.004$ & 0.027 \\
\hline $\mathrm{AA}(\mathrm{g} / \mathrm{d})$ & 761 & $0.15 \pm 0.01$ & 420 & $0.16 \pm 0.01$ & 341 & $0.14 \pm 0.005$ & 0.019 \\
\hline Total fat $(\mathrm{g} / \mathrm{d})$ & 761 & $89.35 \pm 1.27$ & 420 & $87.08 \pm 1.50$ & 341 & $92.15 \pm 1.37$ & 0.06 \\
\hline \multicolumn{8}{|l|}{$\begin{array}{l}\text { Nutrient intakes from food } \mathcal{E} \\
\text { supplements }\end{array}$} \\
\hline Total vitamin B6 (mg/d) & 761 & $5.44 \pm 0.56$ & 420 & $5.57 \pm 0.69$ & 341 & $5.28 \pm 0.74$ & 0.86 \\
\hline Total ALA $(g / d)$ & 761 & $1.65 \pm 0.04$ & 420 & $1.55 \pm 0.03$ & 341 & $1.76 \pm 0.07$ & 0.036 \\
\hline Total EPA $(\mathrm{g} / \mathrm{d})$ & 761 & $0.037 \pm 0.004$ & 420 & $0.042 \pm 0.006$ & 341 & $0.031 \pm 0.004$ & 0.1 \\
\hline Total DHA (g/d) & 761 & $0.072 \pm 0.01$ & 420 & $0.080 \pm 0.008$ & 341 & $0.063 \pm 0.004$ & 0.06 \\
\hline \multicolumn{8}{|l|}{ Plasma Variables } \\
\hline ALA $(\mu \mathrm{mol} / \mathrm{L})$ & 850 & $59.87 \pm 1.27$ & 475 & $60.26 \pm 1.64$ & 375 & $59.40 \pm 1.62$ & 0.99 \\
\hline $\mathrm{LA}(\mu \mathrm{mol} / \mathrm{L})$ & 850 & $3375.4 \pm 35.0$ & 475 & $3371.3 \pm 40.6$ & 375 & $3380.4 \pm 36.4$ & 0.9 \\
\hline $\mathrm{EPA}(\mu \mathrm{mol} / \mathrm{L})$ & 849 & $41.12 \pm 1.10$ & 474 & $43.13 \pm 1.83$ & 375 & $38.81 \pm 0.91$ & 0.09 \\
\hline $\mathrm{DHA}(\mu \mathrm{mol} / \mathrm{L})$ & 850 & $114.89 \pm 3.77$ & 475 & $112.71 \pm 4.25$ & 375 & $117.60 \pm 3.58$ & 0.043 \\
\hline $\mathrm{AA}(\mu \mathrm{mol} / \mathrm{L})$ & 850 & $758.70 \pm 6.23$ & 475 & $764.41 \pm 11.74$ & 375 & $751.82 \pm 6.88$ & 0.16 \\
\hline $\mathrm{EPA}+\mathrm{DHA}(\mu \mathrm{mol} / \mathrm{L})$ & 849 & $158.73 \pm 4.88$ & 474 & $158.63 \pm 6.16$ & 375 & $158.86 \pm 4.10$ & 0.52 \\
\hline $\mathrm{EPA} / \mathrm{AA}$ & 849 & $0.054 \pm 0.001$ & 474 & $0.056 \pm 0.002$ & 375 & $0.052 \pm 0.001$ & 0.13 \\
\hline$(\mathrm{EPA}+\mathrm{DHA}) / \mathrm{AA}$ & 849 & $0.209 \pm 0.006$ & 474 & $0.207 \pm 0.006$ & 375 & $0.211 \pm 0.006$ & 0.034 \\
\hline PLP (nmol/L) & 854 & $42.35 \pm 1.88$ & 479 & $51.07 \pm 2.61$ & 375 & $33.52 \pm 1.85$ & 0.0002 \\
\hline PLP category 2,3 & & & & & & & $<0.0001$ \\
\hline$<20 \mathrm{nmol} / \mathrm{L}$ & 175 & $18.6 \pm 1.8$ & 55 & $10.4 \pm 1.9$ & 120 & $29.0 \pm 2.4$ & \\
\hline$\geq 20 \mathrm{nmol} / \mathrm{L}$ & 679 & $81.4 \pm 1.8$ & 424 & $89.6 \pm 1.9$ & 255 & $71.0 \pm 2.4$ & \\
\hline
\end{tabular}

AA, arachidonic acid; ALA, $\alpha$-linolenic acid; DHA, docosahexaenoic acid; EPA, eicosapentaenoic acid; LA, linoleic acid; PLP, pyridoxal 5 '-phosphate; PUFA, polyunsaturated fatty acids; $n$, frequencies; SE, standard error; $\%$, sample-weighted percentages. Sample sizes were presented as unweighted. Values were expressed as arithmetic means or geometric means \pm SE for continuous variables and sample-weighted percentages with SE for categorical variables. Log-transformed values of plasma PUFA and PLP were used for $t$-tests. Number of observations used for t-tests: $n=696$ for nutrient intake variables; $n=683-684$ for plasma PUFA; $n=675$ for plasma PLP. $1 t$-test for comparing the means of dependent variables between men and women. ${ }^{2}$ Rao-Scott F-adjusted chi-square test for examining whether there are differences in proportions between men and women for the PLP category. ${ }^{3} \% \pm$ SE. For nutrient intakes: adjusted for demographic variables (age, race/ethnicity), BMI, socioeconomic variables (PIR, educational attainment), physical activity level, cigarette smoking status, alcohol consumption, prescription medication use, menopausal status. For plasma PUFA: adjusted for demographic variables (age, race/ethnicity), BMI, dietary variables (total fat intake, total intakes of EPA, DHA, ALA, dietary intakes of LA and AA), socioeconomic variables (PIR, educational attainment), physical activity level, cigarette smoking status, alcohol consumption, prescription medication use, menopausal status. For plasma PLP: adjusted for demographic variables (age, race/ethnicity), BMI, dietary variables (total energy intake, total vitamin B6 intake), socioeconomic variables (PIR, educational attainment), physical activity level, cigarette smoking status, alcohol consumption, prescription medication use, menopausal status.

Higher geometric means of plasma DHA concentration and (EPA + DHA)/AA ratio were observed in women than in men ( $p=0.043, p=0.034$ each) after adjusting for demographic and socioeconomic factors, total fat intake, total intakes of EPA, DHA, ALA, dietary intakes of LA and AA, BMI, physical activity level, cigarette smoking status, alcohol 
consumption, prescription medication use, and menopausal status. A geometric mean plasma EPA concentration tended to be higher in men than in women $(p=0.09)$. There were no differences between men and women in plasma concentrations of ALA, LA, AA, $\mathrm{EPA}+\mathrm{DHA}$, and EPA/AA ratio.

A geometric mean plasma PLP concentration was lower in women than in men after adjusting for demographic and socioeconomic factors, total energy intake, total vitamin B6 intake, BMI, physical activity level, cigarette smoking status, alcohol consumption, prescription medication use, and menopausal status $(p=0.0002)$. Vitamin B6 deficiency, defined by plasma PLP concentration $<20 \mathrm{nmol} / \mathrm{L}$, was more common among women than men, with more than a quarter of women with vitamin B6 deficiency $(p<0.0001)$.

\subsection{No Interaction Effects between Gender and Vitamin B6 Intake on Plasma PUFA Concentrations and Ratios}

To assess whether gender modifies the association between vitamin B6 intake and plasma PUFA, we included an interaction term of gender*B6 intake in multivariate linear regression models fully adjusted for demographic and socioeconomic factors, total fat intake, total intakes of EPA, DHA, and ALA, dietary intakes of LA and AA, BMI, physical activity level, cigarette smoking status, alcohol consumption, prescription medication use, and menopausal status. There was no significant interaction between gender and vitamin B6 intake on EPA $(P$-interaction $=0.37), \mathrm{DHA}(P$-interaction $=0.11), \mathrm{AA}\left(P\right.$ - $\left._{\text {interaction }}=0.86\right), \mathrm{EPA}+$ DHA $\left(P_{- \text {interaction }}=0.14\right)$, EPA $/ \mathrm{AA}\left(P_{- \text {interaction }}=0.34\right)$, and $(\mathrm{EPA}+\mathrm{DHA}) / \mathrm{AA}\left(P_{\text {-interaction }}=\right.$ 0.11 ), respectively (data not shown). These results indicate that the relationship between vitamin B6 intake and plasma EPA, DHA, AA, EPA + DHA, EPA/AA, (EPA + DHA)/AA did not differ between men and women.

\subsection{Associations of Plasma PLP Concentration with Plasma PUFA Concentrations and Ratios, Stratified by Gender}

There was a significant interaction between gender and PLP on EPA $\left(P\right.$-interaction $_{\text {- }}$ $0.004)$, DHA $\left(P_{\text {-interaction }}=0.020\right), \mathrm{EPA}+\mathrm{DHA}\left(P_{\text {-interaction }}=0.010\right), \mathrm{EPA} / \mathrm{AA}\left(P_{\text {-interaction }}=\right.$ $0.002)$, and $(\mathrm{EPA}+\mathrm{DHA}) / \mathrm{AA}\left(P_{\text {-interaction }}=0.004\right)$, respectively, but not AA $\left(P_{\text {-interaction }}=\right.$ 0.37), in the fully adjusted model, indicating that the association between PLP and EPA, $\mathrm{DHA}, \mathrm{EPA}+\mathrm{DHA}, \mathrm{EPA} / \mathrm{AA}$, and $(\mathrm{EPA}+\mathrm{DHA}) / \mathrm{AA}$, but not AA, differs by gender (Table 3).

The relationships between plasma PLP concentration and plasma PUFA concentrations and ratios by gender are presented in Table 3 . In gender-stratified bivariate and multivariate regression models, plasma PLP was positively associated with plasma EPA, DHA, EPA + DHA, EPA/AA, (EPA + DHA)/AA, respectively, in men only. In the fully adjusted model 2 , the association of PLP with EPA $(b=0.104, p=0.0004)$, DHA $(b=0.058, p=0.036)$, EPA + DHA $(b=0.073, p=0.005)$, EPA $/$ AA $(b=0.099, p=0.0002)$, and (EPA + DHA)/AA $(\mathrm{b}=0.068, p=0.005)$ were significant. In contrast, there were no significant associations between plasma PLP and EPA, DHA, EPA + DHA, EPA/AA, and (EPA + DHA)/AA in women.

It is interpreted that, among men, the log plasma concentrations of EPA, DHA, EPA + DHA and ratios of EPA/AA and (EPA + DHA)/AA increase by 0.138 SD, 0.101 SD, 0.125 SD, 0.144 SD, and 0.123 SD, respectively, for 1 SD increase in log plasma PLP concentration in the full model 2. Based on the regression coefficients for men, the estimated effects of PLP on PUFA changed between the unadjusted model 0 and the full model 2. In men, the standardized coefficient for EPA fell from 0.203 in model 0 to 0.138 in model 2, for DHA from 0.169 to 0.101 , for EPA + DHA from 0.198 to 0.125 , for EPA/AA from 0.215 to 0.144 , and for (EPA + DHA)/AA from 0.198 to 0.123 . These suggest that demographic, socioeconomic, dietary (total fat intake, total intakes of EPA, DHA, and ALA, dietary intakes of LA and AA) factors, physical activity level, cigarette smoking status, alcohol consumption, prescription medication use, and BMI may mediate the association between PLP and EPA, DHA, EPA, EPA + DHA, EPA/AA, and (EPA + DHA)/AA, respectively, among men. 
Table 3. Linear regression models: the association of plasma PLP concentration with plasma PUFA concentrations and ratios, stratified by gender among US adults aged 20-59 years, NHANES 2003-2004.

\begin{tabular}{|c|c|c|c|c|c|c|c|c|c|}
\hline & \multicolumn{4}{|c|}{ Men $(n=484)$} & \multicolumn{4}{|c|}{ Women $(n=380)$} & \multirow[b]{2}{*}{$P_{- \text {interaction }}{ }^{1}$} \\
\hline & $\beta$ & b $(95 \%$ CI $)$ & $\mathbf{R}^{2}$ & $p$ & $\beta$ & B $(95 \%$ CI $)$ & $\mathbf{R}^{2}$ & $p$ & \\
\hline & \multicolumn{9}{|c|}{ Plasma EPA $(\mu \mathrm{mol} / \mathrm{L})$} \\
\hline $\begin{array}{c}\text { Plasma PLP } \\
\text { (nmol/L) }\end{array}$ & & & & & & & & & 0.004 \\
\hline Model 0 & 0.203 & $0.155(0.105,0.204)$ & 0.04 & $<0.0001$ & -0.0001 & $-0.0001(-0.064,0.064)$ & $2.1 \times 10^{-8}$ & 0.998 & \\
\hline Model 1 & 0.180 & $0.135(0.079,0.190)$ & 0.24 & 0.0001 & -0.048 & $-0.026(-0.111,0.059)$ & 0.18 & 0.525 & \\
\hline Model 2 & \multicolumn{9}{|c|}{ Plasma DHA $(\mu \mathrm{mol} / \mathrm{L})$} \\
\hline $\begin{array}{c}\text { Plasma PLP } \\
(\mathrm{nmol} / \mathrm{L})\end{array}$ & & & & & & & & & 0.020 \\
\hline Model 0 & 0.169 & $0.096(0.032,0.160)$ & 0.03 & 0.006 & -0.038 & $-0.016(-0.090,0.058)$ & 0.001 & 0.65 & \\
\hline Model 1 & 0.165 & $0.094(0.039,0.148)$ & 0.27 & 0.002 & -0.055 & $-0.023(-0.116,0.069)$ & 0.19 & 0.60 & \\
\hline Model 2 & 0.101 & $0.058(0.004,0.112)$ & \multicolumn{6}{|c|}{ Plasma AA $(\mu \mathrm{mol} / \mathrm{L})$} & \\
\hline $\begin{array}{l}\text { Plasma PLP } \\
\text { (nmol/L) }\end{array}$ & & & & & & & & & 0.365 \\
\hline Model 0 & 0.020 & $0.007(-0.029,0.043)$ & 0.0004 & 0.70 & -0.104 & $-0.028(-0.057,0.0005)$ & 0.01 & 0.05 & \\
\hline Model 1 & 0.025 & $0.008(-0.029,0.046)$ & 0.11 & 0.65 & -0.095 & $-0.027(-0.057,0.004)$ & 0.08 & 0.08 & \\
\hline Model 2 & 0.013 & $0.004(-0.034,0.042)$ & 0.14 & 0.81 & -0.085 & $-0.023(-0.059,0.012)$ & 0.14 & 0.19 & \\
\hline & \multicolumn{9}{|c|}{ Plasma EPA + DHA $(\mu \mathrm{mol} / \mathrm{L})$} \\
\hline $\begin{array}{c}\text { Plasma PLP } \\
\text { (nmol/L) }\end{array}$ & & & & & & & & & 0.010 \\
\hline Model 0 & 0.198 & $0.115(0.060,0.170)$ & 0.04 & 0.001 & -0.024 & $-0.010(-0.077,0.057)$ & 0.001 & 0.76 & \\
\hline Model 1 & 0.186 & $0.108(0.059,0.156)$ & 0.29 & 0.0003 & -0.052 & $-0.021(-0.109,0.066)$ & 0.19 & 0.61 & \\
\hline Model 2 & 0.125 & \multicolumn{8}{|c|}{ Plasma EPA/AA ratio } \\
\hline $\begin{array}{c}\text { Plasma PLP } \\
\text { (nmol/L) }\end{array}$ & & & & & & & & & 0.002 \\
\hline Model 0 & 0.215 & $0.147(0.102,0.191)$ & 0.05 & $<0.0001$ & 0.062 & $0.028(-0.037,0.094)$ & 0.004 & 0.37 & \\
\hline Model 1 & 0.186 & $0.125(0.079,0.171)$ & 0.29 & $<0.0001$ & 0.001 & $0.001(-0.074,0.076)$ & 0.16 & 0.99 & \\
\hline Model 2 & 0.144 & $0.099(0.056,0.142)$ & 0.32 & 0.0002 & -0.011 & $-0.005(-0.092,0.082)$ & 0.20 & 0.90 & \\
\hline & \multicolumn{9}{|c|}{ Plasma (EPA + DHA)/AA ratio } \\
\hline $\begin{array}{c}\text { Plasma PLP } \\
(\mathrm{nmol} / \mathrm{L})\end{array}$ & & & & & & & & & 0.004 \\
\hline Model 0 & 0.198 & $0.107(0.055,0.160)$ & 0.04 & 0.001 & 0.054 & $0.018(-0.043,0.080)$ & 0.003 & 0.53 & \\
\hline Model 1 & 0.181 & $0.098(0.053,0.144)$ & 0.32 & 0.0003 & 0.016 & $0.005(-0.064,0.074)$ & 0.19 & 0.87 & \\
\hline Model 2 & 0.123 & $0.068(0.024,0.113)$ & 0.36 & 0.005 & -0.001 & $-0.0004(-0.070,0.069)$ & 0.22 & 0.99 & \\
\hline
\end{tabular}

AA, arachidonic acid; DHA, docosahexaenoic acid; EPA, eicosapentaenoic acid; PLP, pyridoxal $5^{\prime}$-phosphate; PUFA, polyunsaturated fatty acids; $b$, unstandardized regression coefficient; $\beta$, standardized regression coefficients; $95 \% \mathrm{CI}, 95 \%$ confidence intervals; $P$-int., $P$-interaction; $\mathrm{R}^{2}$, the coefficient of determination. Sample sizes are presented as unweighted. Plasma PUFA and PLP variables were log-transformed. Standardized coefficients $(\beta)$ are to be interpreted as the change in log-transformed plasma PUFA concentrations and ratios in standard deviation (SD) for 1 SD of change in log-transformed plasma PLP concentration. For model 0, the unadjusted $\mathrm{R}^{2}$ is presented, and for models 1 and 2, the adjusted $\mathrm{R}^{2}$ is presented. Model 0: unadjusted. Model 1: adjusted for demographic variables (age, race/ethnicity), BMI, dietary variables (total fat intake, total intakes of EPA, DHA, and ALA, dietary intakes of LA and AA), menopausal status (for women). Model 2: adjusted for all variables in model 1 plus socioeconomic variables (PIR, educational attainment), physical activity level, cigarette smoking status, alcohol consumption, and prescription medication use. ${ }^{1} p$-value for the interaction term gender*PLP on plasma PUFA in the fully adjusted model 2. Number of observations used in the analysis of each model: Model 0: $n=469-470$ for men, $n=370$ for women; Model 1: $n=403-404$ for men, $n=327$ for women; Model 2: $n=380-381$ for men, $n=294$ for women.

Based on the results of the coefficient of determination, adjusted $\mathrm{R}^{2}\left(\mathrm{a} \mathrm{R}^{2}\right)$, for men in the partial model 1, 24\%, 27\%, 29\%, 29\%, and 32\% of the variance in EPA, DHA, EPA + DHA, EPA/AA, and (EPA + DHA)/AA, respectively, is explained by demographic, dietary factors and BMI. After further adjustment in the full model 2, in men, the additional $3 \%, 4 \%$, $3 \%, 3 \%, 4 \%$ of the variance in EPA, DHA, EPA + DHA, EPA/AA, (EPA + DHA) $/ \mathrm{AA}$ each is further explained by socioeconomic factors, physical activity level, cigarette smoking status, alcohol consumption, and prescription medication use, in addition to the model 1 covariates $\left(\mathrm{aR}^{2}=0.27, \mathrm{aR}^{2}=0.31, \mathrm{aR}^{2}=0.32 . \mathrm{aR}^{2}=0.32, \mathrm{aR}^{2}=0.36\right.$, respectively).

Lastly, the relationship between PLP and AA was not affected by gender. No significant association existed between PLP and AA in all models for both men and women. 


\section{Discussion}

This present study observed gender differences in the relationships between plasma PLP and plasma EPA, DHA, EPA + DHA, EPA/AA, and (EPA + DHA)/AA, with the significant positive associations in men only, but not in women, among US young and middle-aged adults after adjusting for demographic, socioeconomic and dietary factors, physical activity level, cigarette smoking status, alcohol consumption, prescription medication use, and BMI. In addition, the association between vitamin B6 intake and the selected PUFA was not affected by gender. To the best of our knowledge, this study is the first population-level observational study to report the gender differences in the relationship between vitamin B6 status, measured by plasma PLP, and plasma PUFA levels in adults aged 20-59 years.

Compared with men, a mean plasma DHA concentration was higher in women, which is supported by the studies describing that women had higher contributions of DHA to plasma lipids than men $[14,20,24]$. In addition, vitamin B6 intake was similar in both men and women in this study, but the mean plasma PLP level was lower in women than in men $(33.5 \mathrm{nmol} / \mathrm{L}$ for women, $51.1 \mathrm{nmol} / \mathrm{L}$ for men). The differences in plasma PLP levels between them may be partially attributable to the prevalence of vitamin B6 deficiency (defined by plasma PLP $<20 \mathrm{nmol} / \mathrm{L}$ ) for women, which was approximately three times higher than for men (29.0\% for women, $10.4 \%$ for men).

Vitamin B6 serves as a coenzyme in the form of PLP for various metabolic reactions, including the synthesis of hemoglobin and neurotransmitters, interconversion of amino acids, gluconeogenesis, and metabolism of tryptophan, one-carbon units, and nucleic acids [67-69]. PUFA, such as EPA, DHA, and AA, provide important structural components of cell membranes [14,15] and exert immunomodulatory functions in humans [15,17]. EPA (n-3 PUFA) and AA (n-6 PUFA) can be synthesized from the precursors, ALA and LA, respectively, in the series of desaturation and elongation reactions catalyzed by elongases and desaturases such as $\Delta 6$-desaturase (D6D) and $\Delta 5$ desaturase (D5D) $[16,24]$. DHA is further converted from docosapentaenoic acid (DPA; 22:5n-3) via chain elongation, desaturation (by D6D), and peroxisomal $\beta$-oxidation [24]. D6D is the rate-limiting step for the biosynthesis of longer chain PUFA, including EPA and DHA; it is influenced by PLP status [12,70,71]. Although the underlying mechanisms of how vitamin B6 regulates D6D has not been fully understood yet [71], it may be speculated that inadequate vitamin B6 status could result in lowering the activity of D6D, thereby leading to the altered compositions of n-3 and n-6 PUFA.

An animal study showed that the D6D activity in male rats fed B6-deficient diets was lower than in the pair-fed control, suggesting low vitamin B6 status disturbed metabolic conversions from LA to AA and from ALA to EPA and DHA, with more reduction in DHA [8]. An in vitro study demonstrated that the relative mRNA expressions of FADS2 (D6D) and FADS1 (D5D) genes were lower in vitamin B6-restricted human hepatoma cells than in control [71]. Further, a case-control study with healthy men and women (21-60 years) reported that D6D activity plus D5D activity (EPA/ALA; enzyme activity measured by a product/precursor ratio) and the second D6D activity (DHA/DPA) were lower in a group with low serum vitamin B6 status (pyridoxine $+\mathrm{PLP}<3 \mu \mathrm{g} / \mathrm{L} ; n=21$ ) than in a control group with normal B6 status $(n=22)$, although plasma PUFA compositions in the group with low B6 status were not different from the control group [9]. These previous findings imply that vitamin B6 status may influence fatty acid desaturation, possibly via PLP-dependent D6D catalyzing PUFA synthesis [5,8,9,71]. Therefore, in part, these may explain the positive associations between plasma PLP and PUFA for men in this study (Table 3).

This study revealed the significant positive associations between plasma PLP and plasma EPA, DHA, EPA/AA, and (EPA + DHA)/AA in men alone, not in women. D6D activity may be regulated by nutritional and non-nutritional factors, including glucose, alcohol, age, estrogen, insulin, etc. [24,72,73]. Besides, the status of iron, which is located at every terminal protein of the D6D enzyme complex [74], was shown to influence the activity 
of D6D [75-78]. Evidence from animal and human studies has indicated that low iron levels, such as iron depletion or iron deficiency, may adversely affect PUFA synthesis [75-79]. It is noteworthy that the aforementioned study by Krajcovicova-Kudlackova et al. [9] demonstrated that the D6D activity (EPA/ALA, DHA/DPA) was positively correlated with serum iron levels. Moreover, the loss of D6D activity and the inhibition effect on PUFA synthesis were more pronounced in the group with low serum iron levels $(<12 \mu \mathrm{mol} / \mathrm{L}$ for men, $<10 \mu \mathrm{mol} / \mathrm{L}$ for women; $n=16$ ) than in the group with low vitamin B6 level. Although data on the relationship between iron and PUFA metabolism are limited, the evidence thus far suggests that low iron status as well as low vitamin B6 status might negatively affect PUFA metabolism [9,75-80]. Furthermore, the present study showed that, compared with men, women had not only the lower mean plasma PLP concentration but also the low serum iron concentration, with the greater prevalence of low vitamin B6 and iron status for women (Table 2; Table S3), which is in agreement with the studies showing the greater prevalence of low iron status in women than in men [81,82]. Thus, the non-significant association of vitamin B6 status and PUFA in women, unlike men, in this study might be explained possibly due to the interaction between iron and PUFA metabolism [75-79]. The combination of vitamin B6 deficiency and low iron status might impact much more adversely on PUFA synthesis in women than in men. To confirm this, future research is necessary to explore whether iron could be another contributing factor to the gender differences in the relationship between vitamin B6 and PUFA metabolism.

Since plasma PLP can be reduced by inflammation [40], the differences in plasma PLP concentration between men and women may be, in part, mediated by inflammation. The proportion of elevated C-reactive protein (CRP) concentration ( $\geq 3 \mathrm{mg} / \mathrm{L} \mathrm{CRP})$, indicative of inflammation [83], was higher in women than in men (data not shown).

In particular, EPA and AA may play a critical role in regulating inflammatory responses by serving as precursors of EPA-derived and AA-derived eicosanoids, respectively [15]. AA promotes platelet aggregation and inflammatory reactions, whereas EPA exerts anti-inflammatory effects and acts as an antagonistic regulator against AA [15]. EPA and DHA also generate resolvins, which have anti-inflammatory and inflammationresolving properties [15]. Further, circulating EPA level was inversely associated with inflammatory markers and cardiovascular disease (CVD) incidence [27]; plasma EPA/AA is considered predictive of CVD risk [84,85] and chronic inflammation, with a higher EPA/AA ratio corresponding to lower levels of inflammation [85]. Besides, vitamin B6 status was inversely associated with inflammation $[25,26]$. This study revealed significant positive associations between plasma PLP and EPA, DHA, and EPA/AA in men (Table 3), which may imply a possible interrelationship between vitamin B6 status and blood PUFA levels and inflammatory diseases in men. However, the interconnection among vitamin B6, PUFA, and inflammation is unclear, and it remains to be answered whether inflammation in relation to vitamin B6 and PUFA would differ by gender.

This study has several limitations. First, there are remaining suspected confounders that were not measured to examine the association between plasma PLP and plasma PUFA. This study did not include lifestyle habits, such as vegetarianism, veganism, folate, vitamin B12, homocysteine, and methylmalonic acid in the assessment. Vegetarianism and veganism may influence plasma PUFA concentrations, and the adherence to such diets may increase the risk of developing vitamin B12 deficiency [86] and lower n-3 PUFA [87]. Vitamin B6 participates in one-carbon metabolism, and the associated metabolites, such as folate, vitamin B12, and homocysteine, are relevant to vitamin B6 deficiency [40]. For this reason, the observed association could still be influenced by residual confounding effects.

Second, in NHANES, fatty acids in plasma and serum were measured in two survey cycles, 2003-2004 and 2011-2012, respectively, while plasma or serum PLP was measured in four different cycles, 2003-2004, 2005-2006, 2007-2008, and 2009-2010. Thus, we utilized the data of fatty acids and PLP from the 2003-2004 cycle, which collected both of them together. However, since, over the past two decades, the use of fish oil supplements increased in US adults [88], it is possible that this could impact the population's level of 
PUFA status. Besides, in the 2003-2004 cycle, plasma fatty acids were measured as part of a surplus specimen project. Only about $45 \%$ of the participants with fasting blood samples had the measurements of plasma ALA, LA, EPA, DHA, or AA. This may result in the potential sample selection bias in this study.

Third, we did not exclude any outliers in the analysis. Five participants were taking unusually high dosages of vitamin B6 supplements. The relative standard error (RSE) was $10.3 \%$ with the outliers included and $7.4 \%$ with the outliers excluded. The estimate with the outliers may still be considered reliable since the RSE did not exceed $20 \%$. For these reasons, those unusually high total vitamin $\mathrm{B} 6$ intake values could be valid and therefore were retained in this study; however, these influential observations may introduce bias.

Fourth, the smaller sample size of the group of women $(n=380)$ than the group of men $(n=484)$ in the gender-stratified analysis might lead to larger sampling variation in women than in men, possibly influencing the results of the nonsignificant association between plasma PLP and plasma PUFA in women and the significant association in men.

Fifth a cross-sectional survey design only demonstrates statistical associations but does not provide causality, making it difficult to establish mechanisms underlying the observations in this study. Sixth, we only utilized plasma fatty acids since other sources of fatty acids, such as erythrocytes, were not available in the NHANES database; unavailability of other direct and functional vitamin B6 biomarkers in the 2003-2004 survey cycle makes analyses limited to plasma PLP.

Nevertheless, this study has strengths. First, the rich, multiethnic NHANES dataset allowed us to use multiple covariates, which may reduce potential sources of bias. Second, although the method of $24 \mathrm{~h}$ dietary recall to assess dietary information is subject to have measurement error associated with the dietary recall method (e.g., underreporting or overreporting of food intakes) [89], the 2 day non-consecutive $24 \mathrm{~h}$ recall used in this study is considered to perform better than a single $24 \mathrm{~h}$ recall since it allows for reducing intra-individual variability in nutrient intakes [90]. Third, since the 2003-2004 cycle is unique to provide data for vitamin B6 intake and plasma PLP and PUFA together, this study took an opportunity to evaluate the relationship between vitamin B6 intake and status and plasma PUFA in the US representative sample.

In conclusion, the significant positive associations between plasma PLP and plasma EPA, DHA, EPA + DHA, EPA/AA, and (EPA + DHA)/AA were found in men only, not in women, among US young and middle-aged adults. Future large-scale prospective studies are necessary to confirm the relationship between gender, vitamin B6, and PUFA status.

Supplementary Materials: The following are available online at https: / / www.mdpi.com/2072-6 $643 / 13 / 2 / 477 / s 1$, Table S1. Pearson correlation coefficients $(\rho)$ between vitamin B6 intake and plasma PLP concentration by gender among US adults aged 20-59 years, NHANES 2003-2004, Table S2. Distributions of original-metric intakes of vitamin B6 and PUFA by gender among US adults aged 20-59 years, NHANES 2003-2004, Table S3. Distributions of serum iron and hemoglobin concentrations by gender among US adults aged 20-59 years, NHANES 2003-2004.

Author Contributions: Conceptualization, A.C., E.B.E., V.N. and H.K.; Formal analysis, H.K.; Methodology, A.C., T.L. and H.K.; Supervision, A.C.; Writing-original draft preparation, H.K.; Writing-review \& editing, A.C., E.B.E., V.N., T.L. and H.K. All authors have read and agreed to the final manuscript.

Funding: This research received no external funding.

Institutional Review Board Statement: Ethical review and approval were waived for this study because the NHANES datasets are de-identified and publicly available, and their use does not require IRB approval.

Informed Consent Statement: Patient consent was waived because, although the NHANES datasets were collected with informed consent, the publicly available data are de-identified, and these are secondary analyses of the publicly available datasets. 
Data Availability Statement: The data used for these secondary analyses of data are publicly available at the CDC webpage: https:/ / wwwn.cdc.gov/nchs/nhanes/Default.aspx.

Conflicts of Interest: The authors declare no conflict of interest.

\section{References}

1. Salmon, W.D. The effect of certain oils in alleviating localised erythematous dermatitis (acrodynia or vitamin B-6 deficiency) in rats. J. Biol. Chem. 1938, 123, 104.

2. Birch, T.W.; György, P. A study of the chemical nature of vitamin B(6) and methods for its preparation in a concentrated state. Biochem. J. 1936, 30, 304-315. [CrossRef] [PubMed]

3. Gross, P. The Rôle of the Unsaturated Fatty Acids in the Acrodynia (Vitamin B6 Deficiency) of the Albino Rat. J. Investig. Dermatol. 1940, 3, 505-522. [CrossRef]

4. Cunnane, S.C.; Manku, M.S.; Horrobin, D.F. Accumulation of linoleic and gamma-linolenic acids in tissue lipids of pyridoxinedeficient rats. J. Nutr. 1984, 114, 1754-1761. [CrossRef]

5. Bordoni, A.; Hrelia, S.; Lorenzini, A.; Bergami, R.; Cabrini, L.; Biagi, P.L.; Tolomelli, B. Dual influence of aging and vitamin B6 deficiency on delta-6-desaturation of essential fatty acids in rat liver microsomes. Prostaglandins Leukot. Essent. Fatty Acids 1998, 58, 417-420. [CrossRef]

6. Cabrini, L.; Bergami, R.; Maranesi, M.; Carloni, A.; Marchetti, M.; Tolomelli, B. Effects of short-term dietary administration of marginal levels of vitamin B(6)and fish oil on lipid composition and antioxidant defences in rat tissues. Prostaglandins Leukot. Essent. Fatty Acids 2001, 64, 265-271. [CrossRef]

7. She, Q.; Hayakawa, T.; Tsuge, H. Effect of Vitamin B6 Deficiency on Linoleic Acid Desaturation in the Arachidonic Acid Biosynthesis of Rat Liver Microsomes. Biosci. Biotechnol. Biochem 1994, 58, 459-463. [CrossRef]

8. Tsuge, H.; Hotta, N.; Hayakawa, T. Effects of vitamin B-6 on (n-3) polyunsaturated fatty acid metabolism. J. Nutr. 2000, 130, 333S-334S. [CrossRef]

9. Krajcovicova-Kudlackova, M.; Klvanova, J.; Dusinska, M. Polyunsaturated Fatty Acid Plasma Content in Groups of General Population with lowvitamin B6 or low iron serum levels. Ann. Nutr. Metab. 2004, 48, 118-121. [CrossRef]

10. Zhao, M.; Lamers, Y.; Ralat, M.A.; Coats, B.S.; Chi, Y.Y.; Muller, K.E.; Bain, J.R.; Shankar, M.N.; Newgard, C.B.; Stacpoole, P.W.; et al. 3rd Marginal vitamin B-6 deficiency decreases plasma (n-3) and (n-6) PUFA concentrations in healthy men and women. J. Nutr. 2012, 142, 1791-1797. [CrossRef]

11. Skeie, E.; Strand, E.; Pedersen, E.R.; Bjorndal, B.; Bohov, P.; Berge, R.K.; Svingen, G.F.; Seifert, R.; Ueland, P.M.; Midttun, O.; et al. Circulating B-vitamins and smoking habits are associated with serum polyunsaturated Fatty acids in patients with suspected coronary heart disease: A cross-sectional study. PLoS ONE 2015, 10, e0129049. [CrossRef] [PubMed]

12. Mujica-Coopman, M.F.; Franco-Sena, A.B.; Farias, D.R.; Vaz, J.S.; Brito, A.; Kac, G.; Lamers, Y. Vitamin B-6 Status in Unsupplemented Pregnant Women Is Associated Positively with Serum Docosahexaenoic Acid and Inversely with the n-6-to-n-3 Fatty Acid Ratio. J. Nutr. 2017, 147, 170-178. [CrossRef] [PubMed]

13. Childs, C.E.; Romeu-Nadal, M.; Burdge, G.C.; Calder, P.C. Gender differences in the n-3 fatty acid content of tissues. Proc. Nutr. Soc. 2008, 67, 19-27. [CrossRef] [PubMed]

14. Lohner, S.; Fekete, K.; Marosvölgyi, T.; Decsi, T. Gender differences in the long-chain polyunsaturated fatty acid status: Systematic review of 51 publications. Ann. Nutr. Metab. 2013, 62, 98-112. [CrossRef] [PubMed]

15. Calder, P.C. Omega-3 fatty acids and inflammatory processes. Nutrients 2010, 2, 355-374. [CrossRef] [PubMed]

16. Bokor, S.; Dumont, J.; Spinneker, A.; Gonzalez-Gross, M.; Nova, E.; Widhalm, K.; Moschonis, G.; Stehle, P.; Amouyel, P.; De Henauw, S.; et al. Single nucleotide polymorphisms in the FADS gene cluster are associated with delta-5 and delta- 6 desaturase activities estimated by serum fatty acid ratios. J. Lipid Res. 2010, 51, 2325-2333. [CrossRef]

17. Calder, P.C. Polyunsaturated fatty acids and inflammatory processes: New twists in an old tale. Biochimie 2009, 91, 791-795. [CrossRef]

18. Crowe, F.L.; Skeaff, C.M.; Green, T.J.; Gray, A.R. Serum n-3 long-chain PUFA differ by sex and age in a population-based survey of New Zealand adolescents and adults. Br. J. Nutr. 2008, 99, 168-174. [CrossRef]

19. Nikkari, T.; Luukkainen, P.; Pietinen, P.; Puska, P. Fatty acid composition of serum lipid fractions in relation to gender and quality of dietary fat. Ann. Med. 1995, 27, 491-498. [CrossRef]

20. Bakewell, L.; Burdge, G.C.; Calder, P.C. Polyunsaturated fatty acid concentrations in young men and women consuming their habitual diets. Br. J. Nutr. 2006, 96, 93-99. [CrossRef]

21. Giltay, E.J.; Gooren, L.J.; Toorians, A.W.; Katan, M.B.; Zock, P.L. Docosahexaenoic acid concentrations are higher in women than in men because of estrogenic effects. Am. J. Clin. Nutr. 2004, 80, 1167-1174. [CrossRef] [PubMed]

22. Burdge, G.C.; Wootton, S.A. Conversion of alpha-linolenic acid to eicosapentaenoic, docosapentaenoic and docosahexaenoic acids in young women. Br. J. Nutr. 2002, 88, 411-420. [CrossRef] [PubMed]

23. Burdge, G.C.; Jones, A.E.; Wootton, S.A. Eicosapentaenoic and docosapentaenoic acids are the principal products of alpha-linolenic acid metabolism in young men*. Br. J. Nutr. 2002, 88, 355-363. [CrossRef] [PubMed]

24. Decsi, T.; Kennedy, K. Sex-specific differences in essential fatty acid metabolism. Am. J. Clin. Nutr. 2011, 94, 1914S-1919S. [CrossRef] [PubMed] 
25. Shen, J.; Lai, C.Q.; Mattei, J.; Ordovas, J.M.; Tucker, K.L. Association of vitamin B-6 status with inflammation, oxidative stress, and chronic inflammatory conditions: The Boston Puerto Rican Health Study. Am. J. Clin. Nutr. 2010, 91, 337-342. [CrossRef] [PubMed]

26. Sakakeeny, L.; Roubenoff, R.; Obin, M.; Fontes, J.D.; Benjamin, E.J.; Bujanover, Y.; Jacques, P.F.; Selhub, J. Plasma pyridoxal5-phosphate is inversely associated with systemic markers of inflammation in a population of U.S. adults. J. Nutr. 2012, 142, 1280-1285. [CrossRef] [PubMed]

27. de Oliveira Otto, M.C.; Wu, J.H.; Baylin, A.; Vaidya, D.; Rich, S.S.; Tsai, M.Y.; Jacobs, D.R., Jr.; Mozaffarian, D. Circulating and dietary omega-3 and omega-6 polyunsaturated fatty acids and incidence of CVD in the Multi-Ethnic Study of Atherosclerosis. J. Am. Heart Assoc. 2013, 2, e000506. [CrossRef]

28. Rathod, K.S.; Kapil, V.; Velmurugan, S.; Khambata, R.S.; Siddique, U.; Khan, S.; Van Eijl, S.; Gee, L.C.; Bansal, J.; Pitrola, K.; et al Accelerated resolution of inflammation underlies sex differences in inflammatory responses in humans. J. Clin. Investig. 2017, 127, 169-182. [CrossRef]

29. Lerner, D.J.; Kannel, W.B. Patterns of coronary heart disease morbidity and mortality in the sexes: A 26-year follow-up of the Framingham population. Am. Heart J. 1986, 111, 383-390. [CrossRef]

30. Card, J.W.; Carey, M.A.; Bradbury, J.A.; DeGraff, L.M.; Morgan, D.L.; Moorman, M.P.; Flake, G.P.; Zeldin, D.C. Gender differences in murine airway responsiveness and lipopolysaccharide-induced inflammation. J. Immunol. 2006, 177, 621-630. [CrossRef]

31. Johnson, C.L.; Paulose-Ram, R.; Ogden, C.L.; Carroll, M.D.; Kruszon-Moran, D.; Dohrmann, S.M.; Curtin, L.R. National health and nutrition examination survey: Analytic guidelines, 1999-2010. Vital Health Stat. 2 2013, 161, 1-24.

32. The Centers for Disease Control and Prevention MEC Interviewers Procedures Manual. Available online: https://wwwn.cdc. gov/nchs/data/nhanes/2003-2004/manuals/MECInterview.pdf (accessed on 22 April 2020).

33. The Centers for Disease Control and Prevention, (CDC) National Health and Nutrition Examination Survey: NCHS Research Ethics Review Board (ERB) Approval. Available online: https://www.cdc.gov/nchs/nhanes/irba98.htm (accessed on 10 December 2020).

34. The Centers for Disease Control and Prevention Laboratory Procedures Manual. Available online: https://wwwn.cdc.gov/nchs / data/nhanes/2003-2004/manuals/lab.pdf (accessed on 22 April 2020).

35. Papsdorf, K.; Brunet, A. Linking Lipid Metabolism to Chromatin Regulation in Aging. Trends Cell Biol. 2019, 29, 97-116. [CrossRef] [PubMed]

36. Toth, M.J.; Tchernof, A. Lipid metabolism in the elderly. Eur. J. Clin. Nutr. 2000, 54 (Suppl. 3), 121. [CrossRef]

37. Fortier, M.; Tremblay-Mercier, J.; Plourde, M.; Chouinard-Watkins, R.; Vandal, M.; Pifferi, F.; Freemantle, E.; Cunnane, S.C. Higher plasma n-3 fatty acid status in the moderately healthy elderly in southern Québec: Higher fish intake or aging-related change in n-3 fatty acid metabolism? Prostaglandins Leukot. Essent. Fatty Acids 2010, 82, 277-280. [CrossRef] [PubMed]

38. Rees, D.; Miles, E.A.; Banerjee, T.; Wells, S.J.; Roynette, C.E.; Wahle, K.W.; Calder, P.C. Dose-related effects of eicosapentaenoic acid on innate immune function in healthy humans: A comparison of young and older men. Am. J. Clin. Nutr. 2006, 83, 331-342. [CrossRef]

39. Bordoni, A.; Biagi, P.L.; Turchetto, E.; Hrelia, S. Aging influence on delta-6-desaturase activity and fatty acid composition of rat liver microsomes. Biochem. Int. 1988, 17, 1001-1009.

40. Ueland, P.M.; Ulvik, A.; Rios-Avila, L.; Midttun, O.; Gregory, J.F. Direct and Functional Biomarkers of Vitamin B6 Status. Annu. Rev. Nutr. 2015, 35, 33-70. [CrossRef]

41. Morris, M.S.; Picciano, M.F.; Jacques, P.F.; Selhub, J. Plasma pyridoxal 5'-phosphate in the US population: The National Health and Nutrition Examination Survey, 2003-2004. Am. J. Clin. Nutr. 2008, 87, 1446-1454. [CrossRef]

42. Enk, L.; Crona, N.; Friberg, L.G.; Samsioe, G.; Silfverstolpe, G. High-dose depot-medroxyprogesterone acetate-effects on the fatty acid composition of serum lecithin and cholesterol ester. Gynecol. Oncol. 1985, 22, 317-323. [CrossRef]

43. Ottosson, U.B.; Lagrelius, A.; Rosing, U.; von Schoultz, B. Relative fatty acid composition of lecithin during postmenopausal replacement therapy-A comparison between ethinyl estradiol and estradiol valerate. Gynecol. Obstet. Investig. 1984, 18, 296-302. [CrossRef]

44. Al, M.D.; van Houwelingen, A.C.; Kester, A.D.; Hasaart, T.H.; de Jong, A.E.; Hornstra, G. Maternal essential fatty acid patterns during normal pregnancy and their relationship to the neonatal essential fatty acid status. Br. J. Nutr. 1995, 74, 55-68. [CrossRef] [PubMed]

45. Kawabata, T.; Kagawa, Y.; Kimura, F.; Miyazawa, T.; Saito, S.; Arima, T.; Nakai, K.; Yaegashi, N. Polyunsaturated Fatty Acid Levels in Maternal Erythrocytes of Japanese Women during Pregnancy and after Childbirth. Nutrients 2017, 9, 245. [CrossRef] [PubMed]

46. The Centers for Disease Control and Prevention MEC In-Person Dietary Interviewers Procedures Manual. Available online: https://wwwn.cdc.gov/nchs/data/nhanes/2003-2004/manuals/DIETARY_MEC.pdf (accessed on 22 April 2020).

47. National Center for Health Statistics National Health and Nutrition Examination Survey. Dietary Supplement Use 30-Day-File 1. 2003-2004 Data Documentation, Codebook, and Frequencies. Available online: https://wwwn.cdc.gov/Nchs/Nhanes/2003-200 4/DSQ1_C.htm (accessed on 31 October 2020).

48. National Center for Health Statistics National Health and Nutrition Examination Survey. 1999-2018 Data Documentation, Codebook, and Frequencies. Dietary Supplement Database-Ingredient Information (DSII). Available online: https://wwwn.cdc. gov/Nchs/Nhanes/1999-2000/DSII.htm (accessed on 31 October 2020). 
49. Naqvi, A.Z.; Davis, R.B.; Mukamal, K.J. Dietary fatty acids and peripheral artery disease in adults. Atherosclerosis 2012, 222, 545-550. [CrossRef] [PubMed]

50. Jäncke, L. Sex/gender differences in cognition, neurophysiology, and neuroanatomy. F1000Res 2018, 7. [CrossRef] [PubMed]

51. Short, S.E.; Yang, Y.C.; Jenkins, T.M. Sex, gender, genetics, and health. Am. J. Public Health 2013, 103 (Suppl. 1), 93. [CrossRef]

52. National Center for Health Statistics National Health and Nutrition Examination Survey. 2003-2004 Data Documentation, Codebook, and Frequencies. Demographic Variables \& Sample Weights (DEMO_C). Available online: https://wwwn.cdc.gov/ Nchs/Nhanes/2003-2004/DEMO_C.htm (accessed on 22 April 2020).

53. The Centers for Disease Control and Prevention Laboratory Procedure Manual: Pyridoxal 5'- Phosphate (PLP) NHANES 20032004. Available online: https:/ / wwwn.cdc.gov/nchs/data/nhanes/2003-2004/labmethods/143_c_met_plp.pdf (accessed on 22 April 2020).

54. Hornung, R.W.; Reed, L.D. Estimation of average concentration in the presence of non-detectable value. Appl. Occup. Environ. Hyg. 1990, 5, 46-51. [CrossRef]

55. Food and Nutrition Board Institute of Medicine A Report of the Standing Committee on the Scientific Evaluation of Dietary Reference Intakes and its Panel on Folate, Other B Vitamins, and Choline and Subcommittee on Upper Reference Levels of Nutrients. Dietary Reference Intakes for Thiamin, Riboflavin, Niacin, Vitamin B6, Folate, Vitamin B12, Pantothenic Acid, Biotin, and Choline; National Academies Press: Washington, DC, USA, 1998.

56. The Centers for Disease Control and Prevention National Health and Nutrition Examination Survey 2003-2004 Data Documentation, Codebook, and Frequencies: Plasma Fatty Acids (Surplus) Data. Available online: https:/ / wwwn.cdc.gov/Nchs/Nhanes / 2003-2004/SSFA_C.htm (accessed on 22 April 2020).

57. Murphy, R.A.; Yu, E.A.; Ciappio, E.D.; Mehta, S.; McBurney, M.I. Suboptimal Plasma Long Chain n-3 Concentrations are Common among Adults in the United States, NHANES 2003-2004. Nutrients 2015, 7, 10282-10289. [CrossRef]

58. Schleicher, R.L.; Sternberg, M.R.; Pfeiffer, C.M. Race-ethnicity is a strong correlate of circulating fat-soluble nutrient concentrations in a representative sample of the U.S. population. J. Nutr. 2013, 143, 966S-976S. [CrossRef]

59. de Groot, R.H.M.; Emmett, R.; Meyer, B.J. Non-dietary factors associated with n-3 long-chain PUFA levels in humans-A systematic literature review. Br. J. Nutr. 2019, 121, 793-808. [CrossRef]

60. Fisk, H.L.; Irvine, M.; Miles, E.A.; Lietz, G.; Mathers, J.C.; Packard, C.J.; Armah, C.K.; Kofler, B.M.; Curtis, P.J.; Minihane, A.M.; et al. Association of oily fish intake, sex, age, BMI and APOE genotype with plasma long-chain n-3 fatty acid composition. Br. J. Nutr. 2018, 120, 23-32. [CrossRef]

61. Stark, K.D.; Park, E.J.; Holub, B.J. Fatty acid composition of serum phospholipid of premenopausal women and postmenopausal women receiving and not receiving hormone replacement therapy. Menopause 2003, 10, 448-455. [CrossRef] [PubMed]

62. Sun, Q.; Ma, J.; Campos, H.; Hankinson, S.E.; Hu, F.B. Comparison between plasma and erythrocyte fatty acid content as biomarkers of fatty acid intake in US women. Am. J. Clin. Nutr. 2007, 86, 74-81. [CrossRef] [PubMed]

63. Raatz, S.K.; Bibus, D.; Thomas, W.; Kris-Etherton, P. Total fat intake modifies plasma fatty acid composition in humans. J. Nutr. 2001, 131, 231-234. [CrossRef] [PubMed]

64. Ogden, C.L.; Carroll, M.D.; Fakhouri, T.H.; Hales, C.M.; Fryar, C.D.; Li, X.; Freedman, D.S. Prevalence of Obesity Among Youths by Household Income and Education Level of Head of Household-United States 2011-2014. MMWR Morb. Mortal. Wkly. Rep. 2018, 67, 186-189. [CrossRef] [PubMed]

65. Willett, W.C.; Howe, G.R.; Kushi, L.H. Adjustment for total energy intake in epidemiologic studies. Am. J. Clin. Nutr. 1997, 65, 1220S-1231S. [CrossRef]

66. Kleinbaum, D.G.; Klein, M. Logistic Regression. Chapter 6. Modeling Strategy Guidelines; Springer: New York, NY, USA, 2010; pp. 169-173.

67. Oxenkrug, G. Insulin resistance and dysregulation of tryptophan-kynurenine and kynurenine-nicotinamide adenine dinucleotide metabolic pathways. Mol. Neurobiol. 2013, 48, 294-301. [CrossRef]

68. Rios-Avila, L.; Nijhout, H.F.; Reed, M.C.; Sitren, H.S.; Gregory, J.F., 3rd. A mathematical model of tryptophan metabolism via the kynurenine pathway provides insights into the effects of vitamin B-6 deficiency, tryptophan loading, and induction of tryptophan 2,3-dioxygenase on tryptophan metabolites. J. Nutr. 2013, 143, 1509-1519. [CrossRef]

69. Paul, L.; Ueland, P.M.; Selhub, J. Mechanistic perspective on the relationship between pyridoxal $5^{\prime}$-phosphate and inflammation. Nutr. Rev. 2013, 71, 239-244. [CrossRef]

70. Nakamura, M.T.; Nara, T.Y. Structure, function, and dietary regulation of delta6, delta5, and delta9 desaturases. Annu. Rev. Nutr. 2004, 24, 345-376. [CrossRef]

71. Zhao, M.; Ralat, M.A.; da Silva, V.; Garrett, T.J.; Melnyk, S.; James, S.J.; Gregory, J.F. 3rd Vitamin B-6 restriction impairs fatty acid synthesis in cultured human hepatoma (HepG2) cells. Am. J. Physiol. Endocrinol. Metab. 2013, 304, 342. [CrossRef]

72. Brenner, R.R. Hormonal modulation of delta6 and delta5 desaturases: Case of diabetes. Prostaglandins Leukot. Essent. Fatty Acids 2003, 68, 151-162. [CrossRef]

73. Brenner, R.R. Nutritional and hormonal factors influencing desaturation of essential fatty acids. Prog. Lipid Res. 1981, 20, 41-47. [CrossRef]

74. Okayasu, T.; Nagao, M.; Ishibashi, T.; Imai, Y. Purification and partial characterization of linoleoyl-CoA desaturase from rat liver microsomes. Arch. Biochem. Biophys. 1981, 206, 21-28. [CrossRef] 
75. Aktas, M.; Elmastas, M.; Ozcicek, F.; Yilmaz, N. Erythrocyte Membrane Fatty Acid Composition in Premenopausal Patients with Iron Deficiency Anemia. J. Oleo Sci. 2016, 65, 225-231. [CrossRef]

76. Tichelaar, H.Y.; Smuts, C.M.; Gross, R.; Jooste, P.L.; Faber, M.; Benadé, A.J. The effect of dietary iron deficiency on the fatty acid composition of plasma and erythrocyte membrane phospholipids in the rat. Prostaglandins Leukot. Essent. Fatty Acids 1997, 56, 229-233. [CrossRef]

77. Cunnane, S.C.; McAdoo, K.R. Iron intake influences essential fatty acid and lipid composition of rat plasma and erythrocytes. J. Nutr. 1987, 117, 1514-1519. [CrossRef]

78. Smuts, C.M.; Tichelaar, H.Y.; van Jaarsveld, P.J.; Badenhorst, C.J.; Kruger, M.; Laubscher, R.; Mansvelt, E.P.; Benade, A.J. The effect of iron fortification on the fatty acid composition of plasma and erythrocyte membranes in primary school children with and without iron deficiency. Prostaglandins Leukot. Essent. Fatty Acids 1995, 52, 59-67. [CrossRef]

79. Stangl, G.I.; Kirchgessner, M. Different degrees of moderate iron deficiency modulate lipid metabolism of rats. Lipids 1998, 33, 889-895. [CrossRef]

80. Rao, G.A.; Larkin, E.C. Role of dietary iron in lipid metabolism. Nutr. Res. 1984, 4, 145-151. [CrossRef]

81. Looker, A.C.; Dallman, P.R.; Carroll, M.D.; Gunter, E.W.; Johnson, C.L. Prevalence of iron deficiency in the United States. JAMA 1997, 277, 973-976. [CrossRef]

82. Centers for Disease Control and Prevention, (CDC) Iron deficiency-United States, 1999-2000. MMWR Morb. Mortal. Wkly. Rep. 2002, 51, 897-899.

83. Blake, G.J.; Rifai, N.; Buring, J.E.; Ridker, P.M. Blood pressure, C-reactive protein, and risk of future cardiovascular events. Circulation 2003, 108, 2993-2999. [CrossRef] [PubMed]

84. Superko, H.R.; Superko, A.R.; Lundberg, G.P.; Margolis, B.; Garrett, B.C.; Nasir, K.; Agatston, A.S. Omega-3 Fatty Acid Blood Levels Clinical Significance Update. Curr. Cardiovasc. Risk Rep. 2014, 8, 407. [CrossRef] [PubMed]

85. Nelson, J.R.; Raskin, S. The eicosapentaenoic acid:arachidonic acid ratio and its clinical utility in cardiovascular disease. Postgrad. Med. 2019, 131, 268-277. [CrossRef] [PubMed]

86. Pawlak, R.; Parrott, S.J.; Raj, S.; Cullum-Dugan, D.; Lucus, D. How prevalent is vitamin B(12) deficiency among vegetarians? Nutr. Rev. 2013, 71, 110-117. [CrossRef] [PubMed]

87. Rosell, M.S.; Lloyd-Wright, Z.; Appleby, P.N.; Sanders, T.A.; Allen, N.E.; Key, T.J. Long-chain n-3 polyunsaturated fatty acids in plasma in British meat-eating, vegetarian, and vegan men. Am. J. Clin. Nutr. 2005, 82, 327-334. [CrossRef] [PubMed]

88. Clarke, T.C.; Black, L.I.; Stussman, B.J.; Barnes, P.M.; Nahin, R.L. Trends in the use of complementary health approaches among adults: United States, 2002-2012. Natl. Health. Stat. Rep. 2015, 10, 1-16.

89. Va, P.; Dodd, K.W.; Zhao, L.; Thompson-Paul, A.M.; Mercado, C.I.; Terry, A.L.; Jackson, S.L.; Wang, C.Y.; Loria, C.M.; Moshfegh, A.J.; et al. Evaluation of measurement error in 24-hour dietary recall for assessing sodium and potassium intake among US adults-National Health and Nutrition Examination Survey (NHANES), 2014. Am. J. Clin. Nutr. 2019, 109, 1672-1682. [CrossRef]

90. De Keyzer, W.; Huybrechts, I.; De Vriendt, V.; Vandevijvere, S.; Slimani, N.; Van Oyen, H.; De Henauw, S. Repeated 24-hour recalls versus dietary records for estimating nutrient intakes in a national food consumption survey. Food Nutr. Res. 2011, 55. [CrossRef] 